\section{A onda de frio de junho de 2012 no Rio Grande do Sul: gênese, duração e temperaturas mínimas registradas}

Eduino Rodrigues da

Costa*

\begin{abstract}
Resumo: A onda de frio é um fenômeno meteorológico de ocorrência irregular no Estado do Rio Grande do Sul e está diretamente associada aos fluxos de ar polares, sobretudo à atuação e domínio atmosférico da Massa Polar Continental. Durante o desenvolvimento do fenômeno geralmente o centro de alta pressão (Anticiclone Polar Atlântico) encontra-se posicionado no interior do continente Sul-americano em território Argentino e seus valores são superiores à $1030 \mathrm{hPa}$. Sabendo da ocorrência de ondas de frio no Rio Grande do Sul, este trabalho teve por objetivo estudar a gênese, duração e as temperaturas mínimas registradas durante a onda de frio ocorrida no Estado entre os dias 06 e 10 de junho de 2012. Destaca-se que a onda de frio de junho de 2012 foi uma das mais fortes dos últimos dez anos, gerando forte anomalia negativa de temperatura no Rio Grande do Sul e grande parte do Cone Sul Sul-americano.
\end{abstract}

\section{The cold wave of june of 2012 in the state of Rio Grande do Sul: genesis, duration and minimum temperatures recorded}

\footnotetext{
Abstract: The cold wave is a meteorological phenomenon of irregular occurrence in the state of Rio Grande do Sul and is directly associated with polar air flows mainly to the performance and mastery of atmospheric Mass Polar Continental. During the development of the phenomenon usually the center of high pressure (Polar Atlantic Anticyclone) is positioned within the South American continent in Argentine territory and their values are higher than $1030 \mathrm{hPa}$. Knowing the occurrence of cold waves in Rio Grande do Sul, this study aimed to study the genesis, duration and minimum temperatures recorded during the cold snap that occurred in the state between days 06 and 10 June 2012. It is noteworthy that the cold wave in June 2012 was one of the strongest of the last ten years, generating strong negative temperature anomaly in Rio Grande do Sul and much of the Cone-Sul of South America.
}

\footnotetext{
* Doutorando do Curso de Pós-Graduação em Geografia da Universidade Estadual Paulista "Júlio de Mesquita Filho" - UNESP/Presidente Prudente-SP.
}

\section{Palavras-chave:}

Fenômeno meteorológico Centro de alta pressão; Onda de frio; Anomalia negativa de temperatura.

Key-Words:

Meteorological phenomenon Center of high pressure; Cold wave, Negative temperature anomaly. 


\section{Introdução}

A onda de frio é um fenômeno meteorológico de difícil previsibilidade, pois depende muito da intensidade e duração dos fluxos de ar polar e também se constituem em fenômenos de marcada irregularidade, pois em certos anos podem não ocorrer e em outros ocorrem mais de uma vez no Estado do Rio Grande do Sul.

Tal irregularidade da ocorrência do fenômeno no Rio Grande do Sul foi comprovada pelo estudo realizado pelos autores Costa ; Sartori ; Fantini (2007) que analisando a ocorrência de ondas de frio na região de Santa Maria/RS por um período de 36 anos (1968 a 2004) notaram que em 10 anos elas não ocorreram.

Outro estudo mais antigo realizado por Machado (1950) englobando todo o Estado do Rio Grande do Sul também destaca e comprova a irregularidade da ocorrência das ondas de frio. De acordo com análises de Machado (1950), num período de tempo de aproximadamente 37 anos (1912 a 1948), verificou-se que em muitos anos as ondas de frio não ocorreram, o que significa que não é um fato climático de ocorrência obrigatoriamente anual no Rio Grande do Sul.

Já em relação à definição e características do fenômeno Machado (1950, p. 35), destaca que:

\footnotetext{
A onda de frio é um fenômeno meteorológico que consiste em uma forte queda de temperatura dentro de certo período, devendo os valores extremos satisfazer determinadas condições, ou seja, dentro de um período de tempo de 24 horas, as temperaturas devem descer a pelo menos $0^{\circ} \mathrm{C}$ nas regiões de maiores altitudes e a $3^{\circ} \mathrm{C}$ nas regiões de menores altitudes do Estado do Rio Grande do Sul.
}

Já para Sartori (2003), as ondas de frio representam períodos de duração variável (de 3 a 9 dias) com fortes quedas de temperatura, embora, na maioria dos casos, não ultrapassem 4 dias. Comumente, ocorrem de fins de outono até o início de primavera, com maior frequência em julho, quando se intensificam os gradientes térmicos entre as altas e baixas latitudes, estimulando as invasões dos anticiclones polares (Anticiclone Polar Atlântico).

Para Romero ; Mendonça (2011, p. 2):

Las ondas de frío corresponden a tipos de tiempo que representan variabilidades
de gran escala espacial y corto plazo temporal, que cubren por tres o más días los
territorios de América del Sur, provocando un brusco y persistente descenso de
temperaturas que acentúan los días de frío típicos del invierno de las zonas australes
templadas y que transportan masas de aire de baja temperatura relativa hasta zonas
tropicales y ecuatoriales.

Em relação à gênese do fenômeno Sartori (2003) afirma que nem todos os domínios de massas polares provocam quedas de temperaturas capazes de caracterizar típicas ondas de frio, pois dependem da trajetória do anticiclone polar ou da posição de seu centro, onde o frio se torna mais intenso.

Assim uma onda de frio se origina quando ocasionalmente, o Anticiclone Polar

Geografia Ensino \& Pesquisa, v. 17, n.2 p. 213-226, maio/ago. 2013

A onda de frio de junho de 2012 no Rio Grande do Sul: gênese, duração e temperaturas... Atlântico (APA) recebe reabastecimento de ar do Anticiclone Polar Pacífico (APP), penetra
pelo interior do continente deslocando-se ao longo da vertente leste dos Andes, ganha características de massa continental e impõe ventos de sudoeste e oeste ao Rio Grande do Sul (SARTORI, 1993).

Sabendo da ocorrência de ondas de frio no Estado do Rio Grande do Sul este artigo teve por objetivo geral analisar a onda de frio ocorrida em junho de 2012, no tocante a sua gênese atmosférica, duração e temperaturas mínimas registradas. 


\section{Materiais e métodos}

Para realizar este trabalho foi feito um levantamento bibliográfico a cerca da ocorrência de ondas de frio no Estado do Rio Grande do Sul, bem como a gênese, duração e características deste fenômeno.

Visando explicar a gênese e evolução sinótica da onda de frio ocorrida no Estado do Rio Grande do Sul entre os dias 04 a10 de junho de 2012, foram obtidas imagens de satélite GOES 12 Canal Realçada das 09 horas GMT, junto ao site do INPE/CPTEC (www.cptec. inpe.br), além de cartas de pressão ao nível do mar das 12 horas GMT disponíveis no site da Marinha do Brasil: http://www.mar.mil.br/dhn/chm/meteo/.

Com o intuito de determinar a duração da onda de frio considerou-se o critério utilizado por Sartori (2003), ou seja, duração de no mínimo três e no máximo nove dias em que as temperaturas mínimas sejam inferiores a $3^{\circ} \mathrm{C}$ e as máximas não ultrapassem $12^{\circ} \mathrm{C}$.

Para analisar as temperaturas mínimas registradas bem como a ocorrência de fenômenos atmosféricos como a geada e a neve no Estado do Rio Grande do Sul durante a ocorrência da onda de frio foram utilizados dados das estações automáticas e convencionais pertencentes ao INMET (Instituto Nacional de Meteorologia), além de informações e imagens publicadas no site da Metsul Meteorologia.

\section{Resultados e discussões}

Gênese atmosférica da onda de frio de junho de 2012

A gênese atmosférica da onda de frio de junho de 2012, assim como todas as demais já registradas no Rio Grande do Sul está relacionada à atuação e domínio atmosférico do Anticiclone Polar Atlântico com trajetória continental e centro de pressão localizado sobre o interior do continente.

Pela análise da carta sinótica (figura 1) do dia 06 de junho de 2012 das 12 horas Z fornecida pela Marinha do Brasil, nota-se que o Anticiclone Polar Pacífico consegue extravasar a Cordilheira dos Andes na latitude do Chile e vem a reforçar o Anticiclone Polar Atlântico que assume trajetória continental e adquire valores de pressão em torno de $1038 \mathrm{hPa}$ (hectopascal).

O tipo de tempo dominante no Estado do Rio Grande do Sul do dia 06 ao dia 10 de junho de 2012durante a ocorrência da Onda de Frio foi o Tempo Anticiclônico Polar continentalizado que de acordo Sartori (2003, p.32):

Associa-se à Massa Polar Continental, assim definida pela trajetória continental assumida pelo Anticiclone Polar Atlântico, que no inverno atinge muitas vezes o estado, trazido pelo reforço no abastecimento do ar polar, quando a Massa Polar Pacífica extravasa sobre a Cordilheira dos Andes, originando um subcentro de alta pressão sobre o norte da Argentina. Esse ar polar proveniente do interior do continente se incorpora à massa da vertente atlântica e determina tipo de tempo caracterizado por ventos de oeste (W) e sudoeste (SW), de leves a moderados, temperaturas mínimas de $0^{\circ} \mathrm{C}$ ou menos, alta pressão, umidade relativa mais baixa que a registrada no Anticiclônico Polar Marítimo. Quando os ventos são leves ou há calmas, ocorrem fortes geadas; quando moderados e regulares, provocam o vento regional conhecido como Minuano. É o tipo de tempo que registra as menores temperaturas na Região Sul do Brasil.

Geografia Ensino \& Pesquisa, v. 17, n. 2 p. 213-226, maio/ago. 2013 
Figura 1 - Carta sinótica do dia 06 de junho de 2012, às 12 horas Z, representativa da Onda de Frio que provocou forte queda de temperatura em toda a Argentina, Uruguai e Rio Grande do Sul.

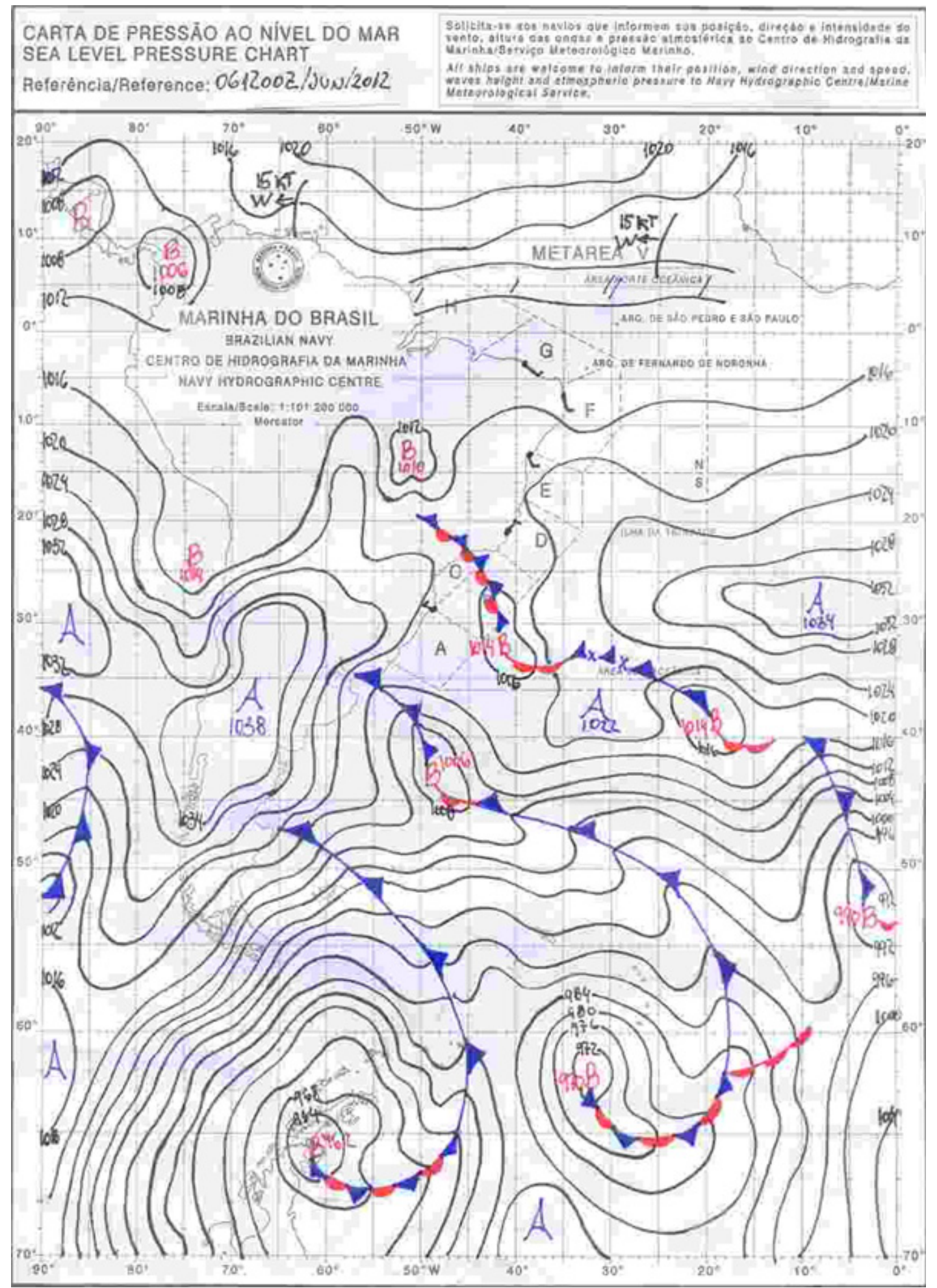

Fonte: Marinha do Brasil (http://www.mar.mil.br/dhn/chm/meteo/).

O tipo de tempo verificado no Rio Grande do Sul a partir do dia 10 até o dia 14 de

Geografia Ensino \& Pesquisa, v. 17, n.2 p. 213-226, maio/ago. 2013

A onda de frio de junho de 2012 no Rio Grande do Sul: gênese, duração e temperaturas.. pelo domínio da Massa Polar Aquecida, registrando aumento das temperaturas máximas $\left(>25^{\circ} \mathrm{C}\right)$ e mínimas $\left(>15^{\circ} \mathrm{C}\right)$, podendo as máximas absolutas serem superiores a $30^{\circ} \mathrm{C}$, com grande amplitude térmica, céu limpo diminuição da umidade 
relativa especialmente à tarde $(<60 \%)$, pressão atmosférica em declínio em relação aos dias anteriores, ventos de leste (E) e nordeste (NE) fracos e calmas, com formação de orvalho. Quando em fase pré-frontal, podem ocorrer chuvas provocadas por Instabilidades Tropicais e Calhas Induzidas, definindo-se, então, os fluxos de norte $(\mathrm{N})$ e noroeste $(\mathrm{NW})$ até muito fortes, muitas vezes com rajadas superiores a 80 $\mathrm{Km} / \mathrm{h}$; a umidade relativa cai a valores inferiores a $45 \%$ e a nebulosidade aumenta gradativamente, surgindo as nuvens altas e médias. É a condição atmosférica em que se define o conhecido Vento Norte.

Figura 2 - Imagem de satélite GOES 12 - Realçada do dia 12 de junho de 2012 às 09 horas, representativo de uma fase pré-frontal e do domínio das condições atmosféricas pela Massa Polar em processo de tropicalização.

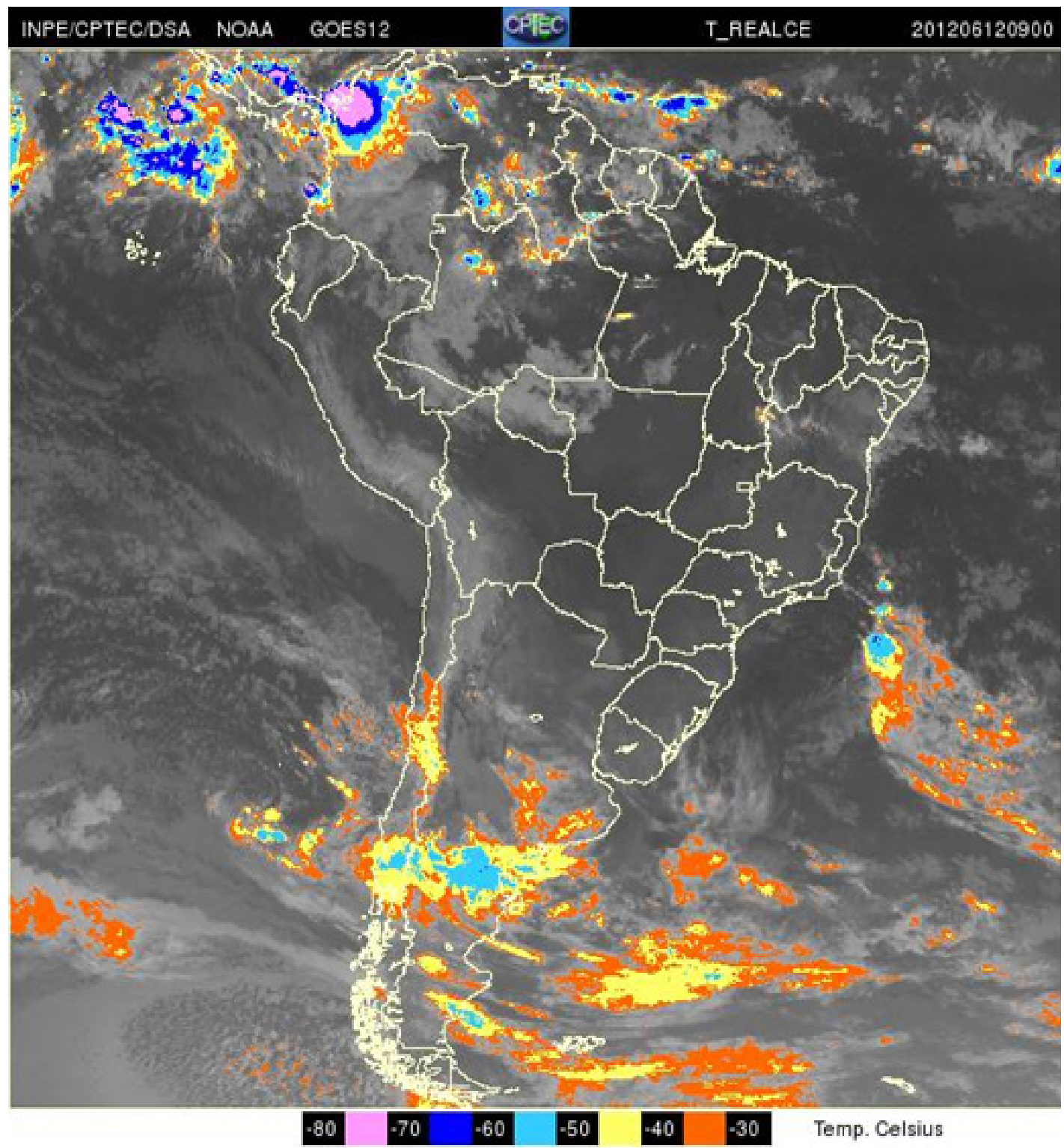

Fonte: CPTEC/INPE.

No dia 15 de junho de 2012, verificou-se a atuação de uma Frente Polar Atlântica no Rio Grande do Sul (figura 3). O tipo de tempo verificado neste dia e no dia seguinte foi o Tempo Frontal de Sudoeste de atuação moderada caracterizado por Sartori (2003, p.34):

Pela passagem normal da Frente Polar Atlântica, sem estacionar sobre o estado do RS, originando densa nebulosidade e chuvas de volume razoável (>50 mm), com relâmpagos e trovoadas, provocadas tanto por nuvens estratiformes (nimbosestratos) quanto cumuliformes (cúmulos-nimbus), após fase pré-frontal bem definida, com ventos do quadrante norte. Dependendo da época do ano e da intensidade do aquecimento pré-frontal, as nuvens cúmulos-nimbos podem provocar temporais

Geografia Ensino \& Pesquisa, v. 17, n. 2 p. 213-226, maio/ago. 2013

Costa, E. R. da. 
com chuvas fortes e queda de granizo. Não ocorre recuo da Frente Polar Atlântica e os ventos geralmente são variáveis em direção e intensidade, com pequena amplitude térmica. A esse tipo de tempo frontal, com duração de, no máximo, dois dias, seguese o domínio da Massa Polar Atlântica.

No dia 15 de junho de 2012, verificou-se a atuação de uma Frente Polar Atlântica no Rio Grande do Sul (figura 3). O tipo de tempo verificado neste dia e no dia seguinte foi o Tempo Frontal de Sudoeste de atuação moderada caracterizado por Sartori (2003, p.34):

Figura 3 - Imagem de satélite GOES 12 - Realçada do dia 15 de junho de 2012 às 09 horas mostrando a atuação de uma FPA (Frente Polar Atlântica) no Rio Grande do Sul.

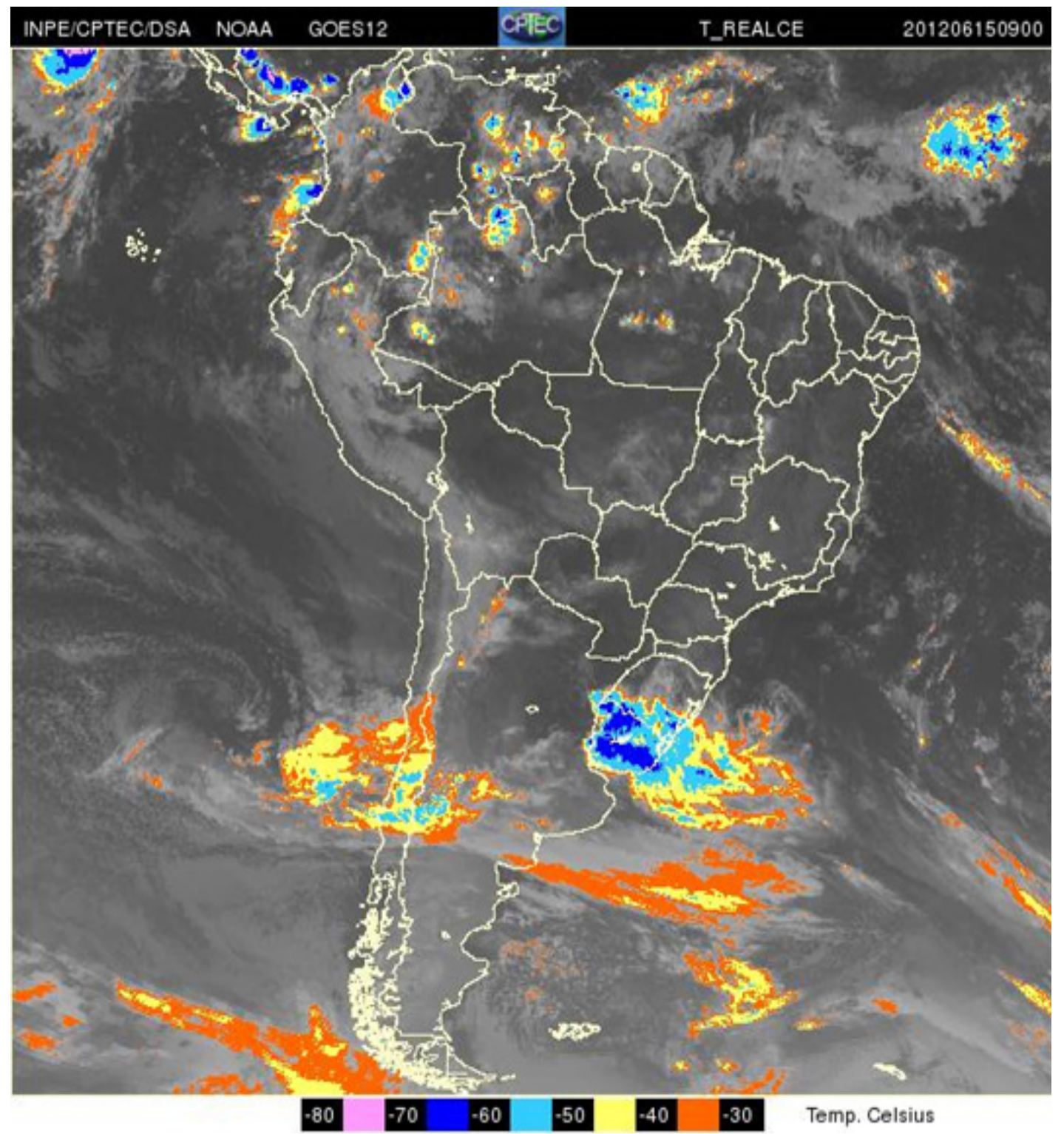

Fonte: CPTEC/INPE.

Geografia Ensino \& Pesquisa, v. 17, n.2 p. 213-226, maio/ago. 2013

A onda de frio de junho de 2012 no Rio Grande do Sul: gênese, duração e temperaturas...
Duração e temperaturas mínimas registradas no Estado do Rio Grande do Sul durante a ocorrência do fenômeno

A onda de frio no Estado do Rio Grande do Sul teve duração de cinco dias tendo início no dia 06de junho e término em 10 de junho de 2012, quando a Massa Polar Continental teve um aquecimento basal passando a condição de Massa Polar Aquecida.

Em relação às temperaturas mínimas registradas nas estações automáticas e 
convencionais pertencentes ao INMET (Instituto Nacional de Meteorologia) localizadas em todas as regiões climáticas do Rio Grande do Sul, nota-se que Santa Rosa localizada na região climática do Alto Uruguai (figura 4) apresentou a menor temperatura mínima do Estado do RS $\left(-3,8^{\circ} \mathrm{C}\right)$ no primeiro dia de ocorrência da onda de frio (dia 06 de junho), conforme o quadro 1. O que explica Santa Rosa apresentar a menor mínima do dia 06 é sua localização geográfica no Vale do Rio Uruguai próximo ao corredor natural das planícies interiores situada entre os Andes e o Planalto Brasileiro que favorece o escoamento do ar frio polar até latitudes mais baixas como a Amazônia. Outro fator é o efeito da continentalidade visto que o interior do continente se aquece e se resfria mais rápido do que o litoral.

A temperatura mínima mais alta no dia 06 de junho foi registrada em Tramandaí $\left(5,9^{\circ} \mathrm{C}\right)$ conforme o quadro 1 . Tramandaí localiza-se na região ecoclimática do Litoral Gaúcho (figura 4), e sofre os efeitos diretos da maritimidade, além de seu relevo estar numa região onde a altitude é baixa (entre 0 e 90 metros acima do nível do mar), conforme a figura 5.

Figura 4 - Regiões ecoclimáticas do Estado do Rio Grande do Sul.

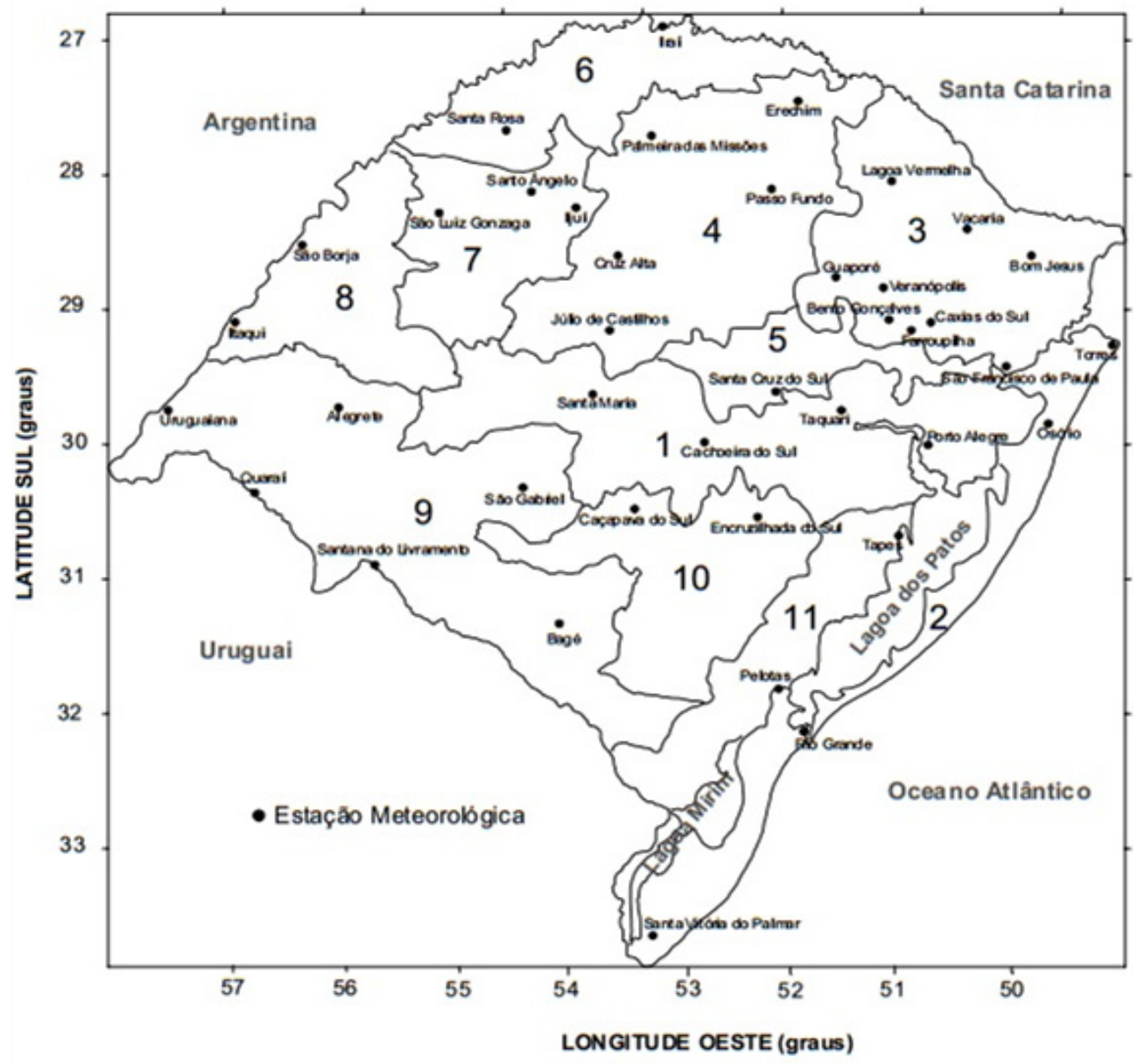

\section{Depressão Central \\ 2. Litoral \\ 3. Planalto Superior e Serra do Nordeste \\ 4. Planalto Médio \\ 5. Encosta Inferior da Serra do Nordeste \\ 6. Alto Uruguai}

7. Missioneira

8. Baixo Vale do Uruguai

9. Campanha

10. Serra do Sudeste

11. Regiảo das Grandes Lagoas

Fonte: Rio Grande do Sul (1994) ; Araújo (2005).

Geografia Ensino \& Pesquisa, v. 17, n. 2 p. 213-226, maio/ago. 2013 
Figura 5 - Mapa Hipsométrico do Estado do Rio Grande do Sul.

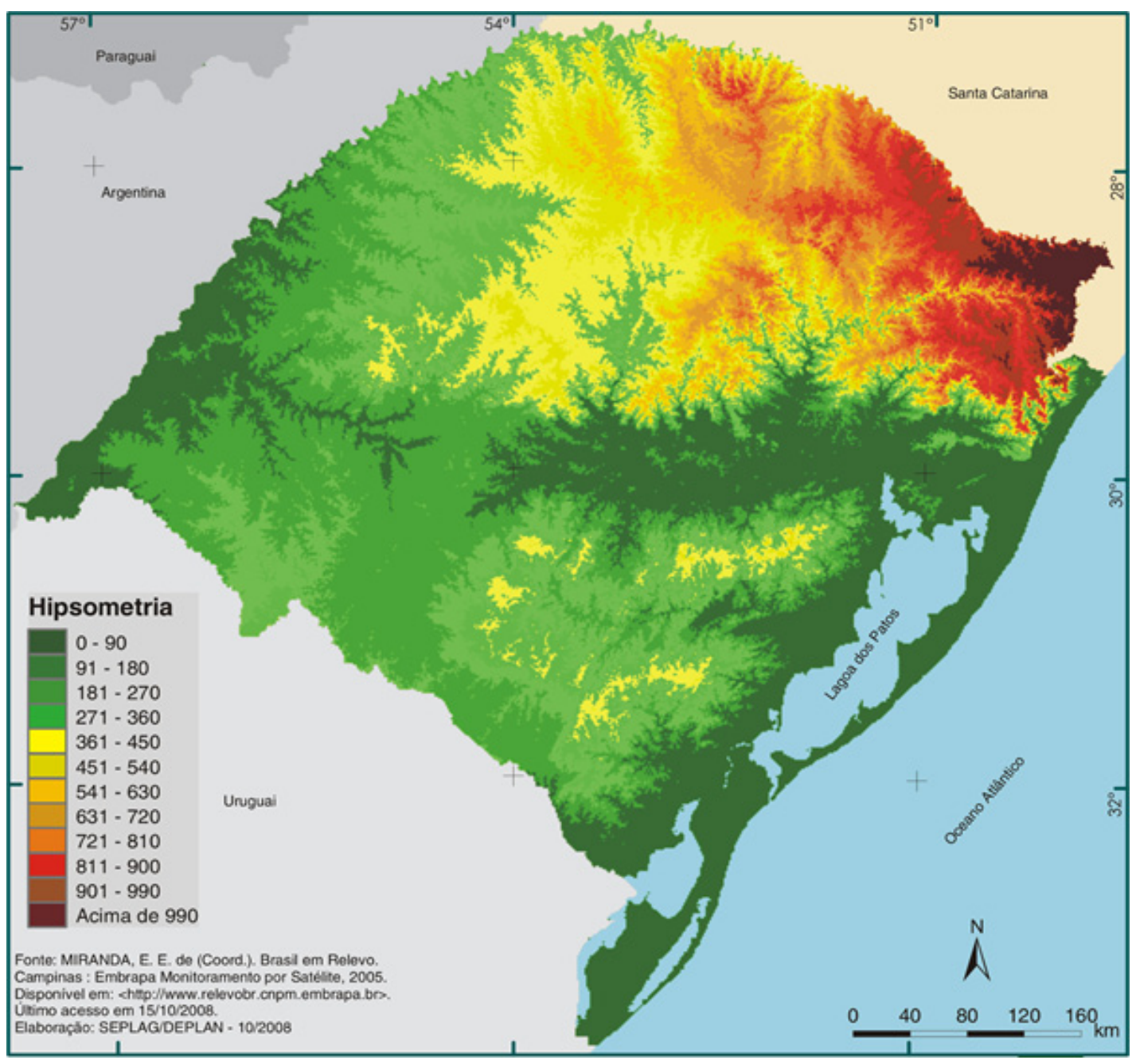

Fonte: SEPLAG/DEPLAN, 2008.

Quadro 1 - Temperaturas mínimas registradas em algumas estações do INMET (Instituto Nacional de Meteorologia) do Estado do Rio Grande do Sul no dia 06 de junho de 2012.

Geografia Ensino \& Pesquisa, v. 17, n.2 p. 213-226, maio/ago. 2013

A onda de frio de junho de 2012 no Rio Grande do Sul: gênese, duração e temperaturas...

$220 \quad$ ISSN 2236-4994

\begin{tabular}{|c|c|c|c|c|c|}
\hline Santa Rosa & $-3,8^{\circ} \mathrm{C}$ & Bagé & $0,7^{\circ} \mathrm{C}$ & Campo Bom & $2,5^{\circ} \mathrm{C}$ \\
\hline Canela & $-3,4^{\circ} \mathrm{C}$ & Dom Pedrito & $0,8^{\circ} \mathrm{C}$ & Livramento & $2,7^{\circ} \mathrm{C}$ \\
\hline Quarai & $-2,2^{\circ} \mathrm{C}$ & Pelotas & $0,8^{\circ} \mathrm{C}$ & Rio Pardo & $2,7^{\circ} \mathrm{C}$ \\
\hline Vacaria & $-2,2^{\circ} \mathrm{C}$ & Teutônia & $1,0^{\circ} \mathrm{C}$ & Santo Augusto & $2,7^{\circ} \mathrm{C}$ \\
\hline Cambará do Sul & $-2,2^{\circ} \mathrm{C}$ & Passo Fundo & $1,0^{\circ} \mathrm{C}$ & São Borja & $2,8^{\circ} \mathrm{C}$ \\
\hline Ibirubá & $-2,0^{\circ} \mathrm{C}$ & Cachoeirinha & $1,2^{\circ} \mathrm{C}$ & Jaguarào & $2,9^{\circ} \mathrm{C}$ \\
\hline Bom Jesus & $-1,6^{\circ} \mathrm{C}$ & F. Westphalen & $1,2^{\circ} \mathrm{C}$ & Porto Alegre & $3,1^{\circ} \mathrm{C}$ \\
\hline São Marcos & $-1,6^{\circ} \mathrm{C}$ & B. Gonçalves & $1,3^{\circ} \mathrm{C}$ & Chuí & $3,1^{\circ} \mathrm{C}$ \\
\hline Ausentes & $-1,2^{\circ} \mathrm{C}$ & Santa Maria & $1,4^{\circ} \mathrm{C}$ & Canguçu & $3,2^{\circ} \mathrm{C}$ \\
\hline Garibaldi & $-0,9^{\circ} \mathrm{C}$ & Erechim & $1,6^{\circ} \mathrm{C}$ & Lajeado & $3,2^{\circ} \mathrm{C}$ \\
\hline Rosário do Sul & $-0,8^{\circ} \mathrm{C}$ & Lagoa Vermelha & $1,6^{\circ} \mathrm{C}$ & Encruzilhada & $3,2^{\circ} \mathrm{C}$ \\
\hline São Gabriel & $-0,8^{\circ} \mathrm{C}$ & Cruz Alta & $1,7^{\circ} \mathrm{C}$ & São L. Gonzaga & $3,6^{\circ} \mathrm{C}$ \\
\hline Farroupilha & $-0,7^{\circ} \mathrm{C}$ & Rio Grande & $2,2^{\circ} \mathrm{C}$ & Torres & $3,7^{\circ} \mathrm{C}$ \\
\hline São F. de Paula & $-0,4^{\circ} \mathrm{C}$ & Soledade & $2,3^{\circ} \mathrm{C}$ & Irai & $4,0^{\circ} \mathrm{C}$ \\
\hline São Leopoldo & $-0,3^{\circ} \mathrm{C}$ & Uruguaiana & $2,4^{\circ} \mathrm{C}$ & Caçapava & $4,4^{\circ} \mathrm{C}$ \\
\hline Três Coroas & $0,2^{\circ} \mathrm{C}$ & Santiago & $2,4^{\circ} \mathrm{C}$ & Santa Vitória & $5,9^{\circ} \mathrm{C}$ \\
\hline Alegrete & $0,3^{\circ} \mathrm{C}$ & Camaquã & $2,5^{\circ} \mathrm{C}$ & Tramandai & $5,9^{\circ} \mathrm{C}$ \\
\hline
\end{tabular}

Fonte: Metsul Meteorologia, 2012.

No dia 06 de junho houve geada generaliza em praticamente todas as regiões ecoclimáticas do Estado do Rio Grande do Sul, conforme registros da Metsul Meteorologia. Na figura 6 têm-se registros da geada em Bom Jesus localizada na região ecoclimática do Planalto Superior 
e Serra do Nordeste, onde se encontram as maiores altitudes do Estado.

No dia 07 de junho (segundo dia de ocorrência da Onda de Frio) verificou-se que as mínimas se apresentaram mais baixas do que no dia anterior (quadro 2). Todas as estações meteorológicas localizadas nas regiões de Planalto e Serras onde as altitudes são mais elevadas registraram temperaturas mínimas negativas. Já as estações localizadas em cidades do Litoral, Depressão Central e próximo das grandes lagoas e lagunas (Patos, Mirim e Mangueira), onde a altitude não é elevada as mínimas foram positivas como em Santa Maria, Porto Alegre, Pelotas, Torres e Tramandaí.

Figura 6 - Geada nos Campos de Cima da Serra no munícipio de Bom Jesus/RS.

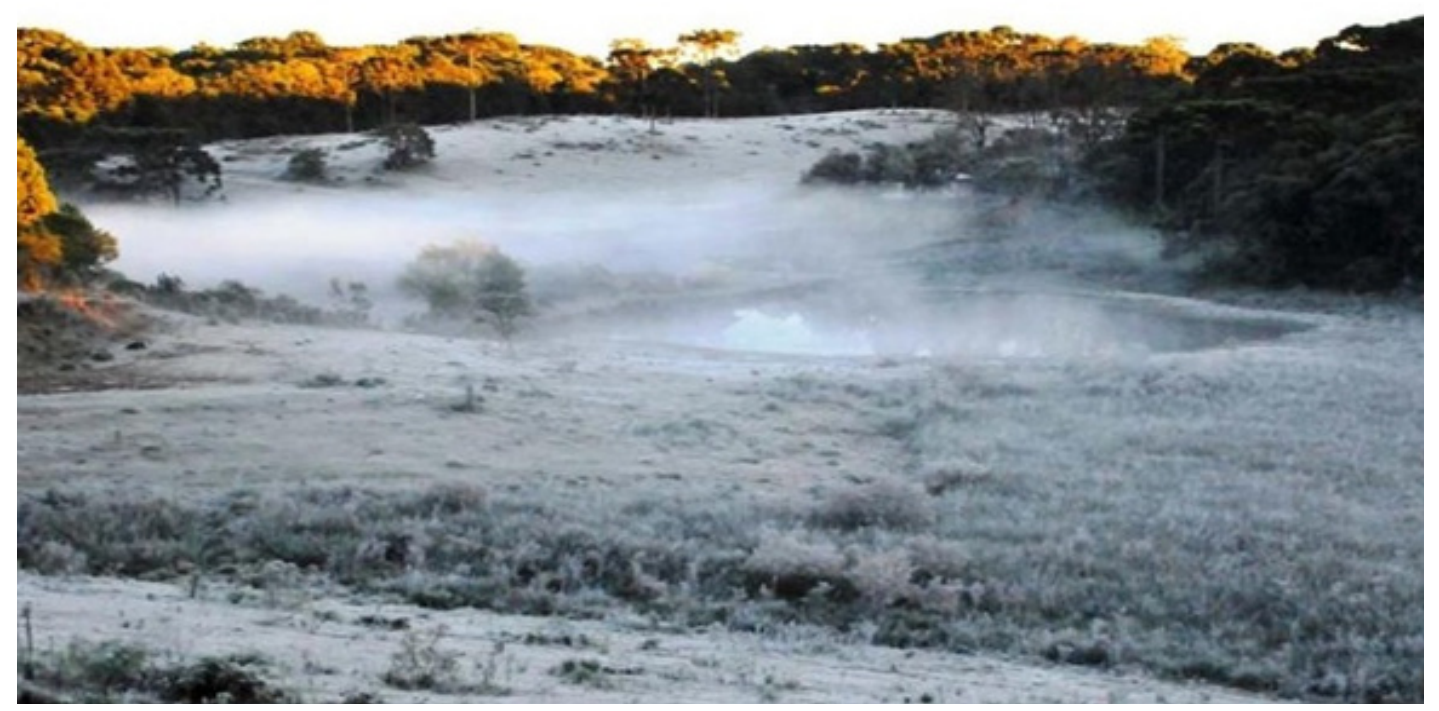

Fonte: Metsul Meteorologia, 2012.

Quadro 2 - Temperaturas mínimas registradas em algumas estações do INMET (Instituto Nacional de Meteorologia) do Estado do Rio Grande do Sul no dia 07 de junho de 2012.

\begin{tabular}{|c|c|c|c|c|c|}
\hline Santa Rosa & $-7,0^{\circ} \mathrm{C}$ & Livramento & $-3,0^{\circ} \mathrm{C}$ & Encruzilhada & $-1,4^{\circ} \mathrm{C}$ \\
\hline Farroupilha & $-5,7^{\circ} \mathrm{C}$ & Dom Pedrito & $-2,9^{\circ} \mathrm{C}$ & Caçapava do Sul & $-1,0^{\circ} \mathrm{C}$ \\
\hline Ausentes & $-5,5^{\circ} \mathrm{C}$ & Alegrete & $-2,8^{\circ} \mathrm{C}$ & Teutônia & $-0,7^{\circ} \mathrm{C}$ \\
\hline Quarai & $-5,0^{\circ} \mathrm{C}$ & Santiago & $-2,7^{\circ} \mathrm{C}$ & Iraí & $-0,4^{\circ} \mathrm{C}$ \\
\hline São F. de Paula & $-4,9^{\circ} \mathrm{C}$ & B. Gonçalves & $-2,7^{\circ} \mathrm{C}$ & São Leopoldo & $-0,4^{\circ} \mathrm{C}$ \\
\hline Cruz Alta & $-4,8^{\circ} \mathrm{C}$ & São Borja & $-2,4^{\circ} \mathrm{C}$ & Jaguarão & $0,2^{\circ} \mathrm{C}$ \\
\hline Bom Jesus & $-4,2^{\circ} \mathrm{C}$ & Santo Augusto & $-2,4^{\circ} \mathrm{C}$ & Rio Pardo & $0,4^{\circ} \mathrm{C}$ \\
\hline Cambará do Sul & $-4,2^{\circ} \mathrm{C}$ & Bagé & $-2,3^{\circ} \mathrm{C}$ & Santa Maria & $0,4^{\circ} \mathrm{C}$ \\
\hline Vacaria & $-4,1^{\circ} \mathrm{C}$ & Passo Fundo & $-2,3^{\circ} \mathrm{C}$ & Lajeado & $0,8^{\circ} \mathrm{C}$ \\
\hline P. das Missōes & $-3,9^{\circ} \mathrm{C}$ & F. Westphalen & $-2,2^{\circ} \mathrm{C}$ & Porto Alegre & $1,6^{\circ} \mathrm{C}$ \\
\hline Săo Gabriel & $-3,9^{\circ} \mathrm{C}$ & Riozinho & $-2,2^{\circ} \mathrm{C}$ & Rio Grande & $1,7^{\circ} \mathrm{C}$ \\
\hline Canela & $-3,9^{\circ} \mathrm{C}$ & Morro Redondo & $-1,8^{\circ} \mathrm{C}$ & Camaquã & $1,8^{\circ} \mathrm{C}$ \\
\hline São Marcos & $-3,8^{\circ} \mathrm{C}$ & Rosário do Sul & $-1,7^{\circ} \mathrm{C}$ & Pelotas & $1,9^{\circ} \mathrm{C}$ \\
\hline Soledade (até 4h) & $-3,5^{\circ} \mathrm{C}$ & São L. Gonzaga & $-1,7^{\circ} \mathrm{C}$ & Chuí & $2,3^{\circ} \mathrm{C}$ \\
\hline Lagoa Vermelha & $-3,4^{\circ} \mathrm{C}$ & Canguçu & $-1,6^{\circ} \mathrm{C}$ & Campo Bom & $2,4^{\circ} \mathrm{C}$ \\
\hline Erechim & $-3,1^{\circ} \mathrm{C}$ & Uruguaiana & $-1,6^{\circ} \mathrm{C}$ & Torres & $3,8^{\circ} \mathrm{C}$ \\
\hline Caxias do Sul & $-3,0^{\circ} \mathrm{C}$ & Três Coroas & $-1,4^{\circ} \mathrm{C}$ & Tramandaí & $3,8^{\circ} \mathrm{C}$ \\
\hline
\end{tabular}

Fonte: Metsul Meteorologia, 2012.

A temperatura mínima mais baixa do dia 07 de junho foi registrada novamente em Santa Rosa $\left(-7^{\circ} \mathrm{C}\right)$ e as mínimas mais altas em Torres e Tramandaí $\left(3,8^{\circ} \mathrm{C}\right)$,conforme o quadro 2. Verifica-se mais uma vez o efeito da altitude e da continentalidade sobre a temperatura do ar, uma vez que Santa Rosa por estar localizada numa área de Planalto e afastada do oceano,apresentou temperaturas mínimas bem mais baixas do que Torres e Tramandaí situadas
Geografia Ensino \& Pesquisa, v. 17, n. 2 p. 213-226, maio/ago. 2013

Costa, E. R. da. 
no Litoral.

Houve ocorrência de geada em quase todas as regiões ecoclimáticas do Estado, conforme a figura 7.

Figura 7 - Geada em Três de Maio cidade situada na mesma região ecoclimática de Santa Rosa, onde foram registradas as temperaturas mais baixas durante a ocorrência da onda de frio.

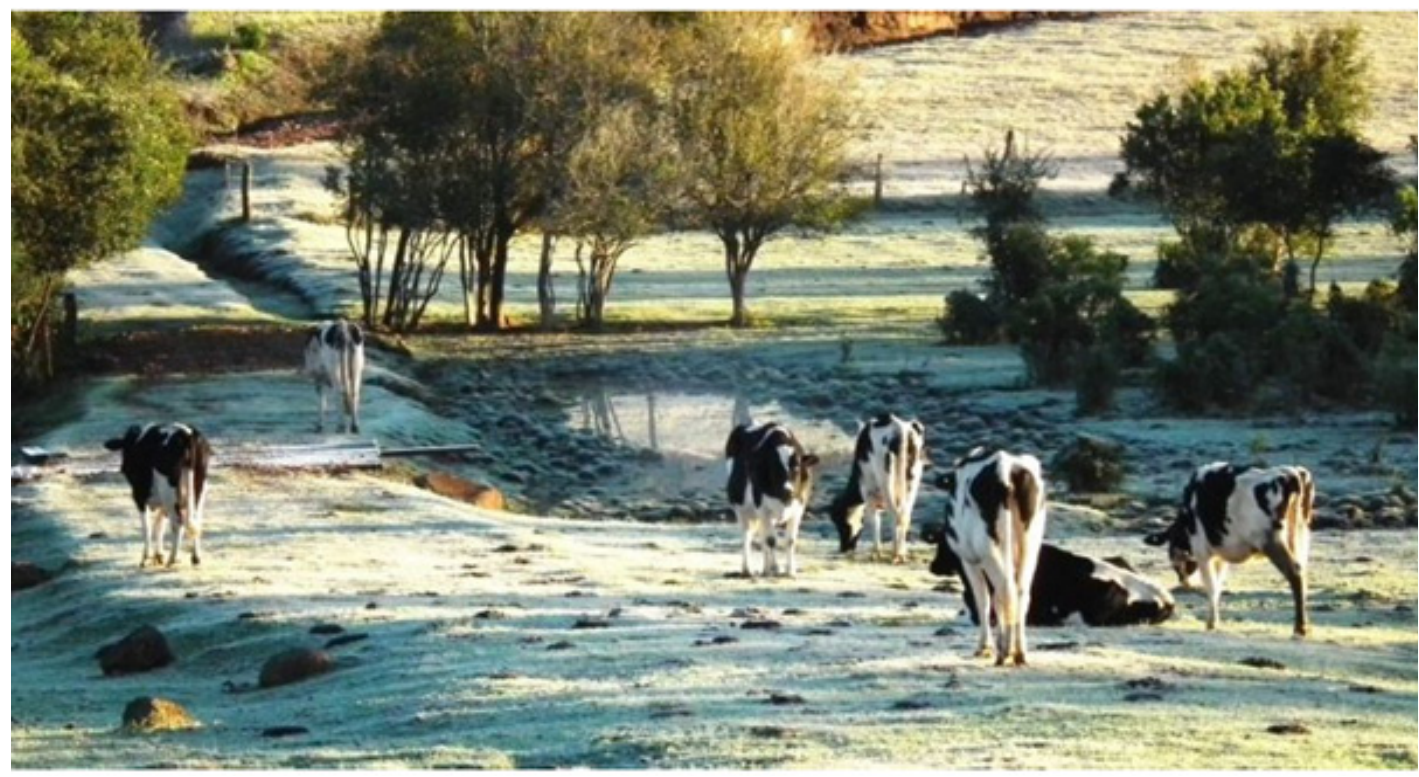

Fonte: Metsul Meteorologia, 2012.

No dia 08 de junho a Onda de Frio assumiu seu pico máximo de resfriamento ocasionando as menores temperaturas mínimas do período (quadro 3). A menor temperatura mínima registrada foi pelo terceiro dia consecutivo em Santa Rosa $\left(-7,8^{\circ}\right)$ quase um grau mais frio do que no dia anterior. Já a maior temperatura mínima foi registrada em Mostardas $\left(2,7^{\circ} \mathrm{C}\right)$ localizada no Litoral e em Caçapava do Sul $\left(2,9^{\circ} \mathrm{C}\right)$ na Serra do Sudeste.

Quadro 3 - Temperaturas mínimas registradas em algumas estações do INMET (Instituto Nacional de Meteorologia) do Estado do Rio Grande do Sul no dia 08 de junho de 2012.

\begin{tabular}{|c|c|c|c|c|c|}
\hline Santa Rosa & $-7,8^{\circ} \mathrm{C}$ & Passo Fundo & $-2,6^{\circ} \mathrm{C}$ & Pelotas & $-1,0^{\circ} \mathrm{C}$ \\
\hline Farroupilha & $-7,7^{\circ} \mathrm{C}$ & Lagoa Vermelha & $-2,5^{\circ} \mathrm{C}$ & Bagé & $-0,9^{\circ} \mathrm{C}$ \\
\hline Canela & $-6,9^{\circ} \mathrm{C}$ & Bento Gonçalves & $-2,4^{\circ} \mathrm{C}$ & Chui & $-0,5^{\circ} \mathrm{C}$ \\
\hline Quarai & $-6,3^{\circ} \mathrm{C}$ & Lagoa Vermelha & $-2,4^{\circ} \mathrm{C}$ & Santiago & $-0,4^{\circ} \mathrm{C}$ \\
\hline Vacaria & $-4,5^{\circ} \mathrm{C}$ & Teutônia & $-2,3^{\circ} \mathrm{C}$ & Porto Alegre & $-0,3^{\circ} \mathrm{C}$ \\
\hline Cruz Alta & $-4,3^{\circ} \mathrm{C}$ & Santa Maria & $-2,0^{\circ} \mathrm{C}$ & Jaguarào & $-0,3^{\circ} \mathrm{C}$ \\
\hline São Marcos & $-4,3^{\circ} \mathrm{C}$ & Santa Rosa & $-2,0^{\circ} \mathrm{C}$ & Torres & $-0,2^{\circ} \mathrm{C}$ \\
\hline São F. de Paula & $-4,0^{\circ} \mathrm{C}$ & Santa Maria & $-1,8^{\circ} \mathrm{C}$ & Camaquã & $-0,1^{\circ} \mathrm{C}$ \\
\hline Cambará & $-4,0^{\circ} \mathrm{C}$ & Campo Bom & $-1,8^{\circ} \mathrm{C}$ & Encruzilhada & $0,2^{\circ} \mathrm{C}$ \\
\hline Rosário do Sul & $-3,9^{\circ} \mathrm{C}$ & Säo Borja & $-1,5^{\circ} \mathrm{C}$ & Santo Augusto & $0,3^{\circ} \mathrm{C}$ \\
\hline Sào Leopoldo & $-3,9^{\circ} \mathrm{C}$ & Igrejinha & $-1,5^{\circ} \mathrm{C}$ & Riozinho & $0,5^{\circ} \mathrm{C}$ \\
\hline Alegrete & $-3,8^{\circ} \mathrm{C}$ & P. das Missōes & $-1,4^{\circ} \mathrm{C}$ & Livramento & $0,5^{\circ} \mathrm{C}$ \\
\hline Ibirubá & $-3,8^{\circ} \mathrm{C}$ & Erechim & $-1,2^{\circ} \mathrm{C}$ & Rio Grande & $0,9^{\circ} \mathrm{C}$ \\
\hline Três Coroas & $-3,5^{\circ} \mathrm{C}$ & F. Westphalen & $-1,2^{\circ} \mathrm{C}$ & Canguçu & $1,0^{\circ} \mathrm{C}$ \\
\hline Uruguaiana & $-3,3^{\circ} \mathrm{C}$ & Irai & $-1,2^{\circ} \mathrm{C}$ & Rio Grande & $1,1^{\circ} \mathrm{C}$ \\
\hline Ausentes & $-3,2^{\circ} \mathrm{C}$ & Rio Pardo & $-1,2^{\circ} \mathrm{C}$ & Santa Vitória & $1,9^{\circ} \mathrm{C}$ \\
\hline São Gabriel & $-3,2^{\circ} \mathrm{C}$ & Lajeado & $-1,1^{\circ} \mathrm{C}$ & Tramandaí & $2,2^{\circ} \mathrm{C}$ \\
\hline Bom Jesus & $-2,8^{\circ} \mathrm{C}$ & Caxias do Sul & $-1,0^{\circ} \mathrm{C}$ & Mostardas & $2,7^{\circ} \mathrm{C}$ \\
\hline Dom Pedrito & $-2,8^{\circ} \mathrm{C}$ & São L. Gonzaga & $-1,0^{\circ} \mathrm{C}$ & Caçapava & $2,9^{\circ} \mathrm{C}$ \\
\hline
\end{tabular}

Fonte: Metsul Meteorologia, 2012.

A onda de frio de junho de 2012 no Rio Grande do Sul: gênese, duração e temperaturas.. 
sul da Bolívia, o Estado do Rio Grande do Sul, Santa Catarina, partes do Paraná e do Mato Grosso do Sul apresentaram as maiores anomalias negativas de temperatura do planeta fora das regiões polares, conforme publicação da Metsul Meteorologia (www.metsul.com). Isto da uma dimensão da magnitude e intensidade da Onda de Frio ocorrida no mês de junho de 2012. $\mathrm{Na}$ figura 8 tem-se o mapa de anomalias térmicas para todo o planeta entre os dias 07 e 08 de junho de 2012, onde se verificou a anomalia térmica no centro da América do Sul, nas regiões anteriormente mencionadas.

Figura 8 - Anomalia negativa de temperatura (em roxo) no Centro da América do Sul no dia 08 de junho de 2012 a maior fora das regiões polares.

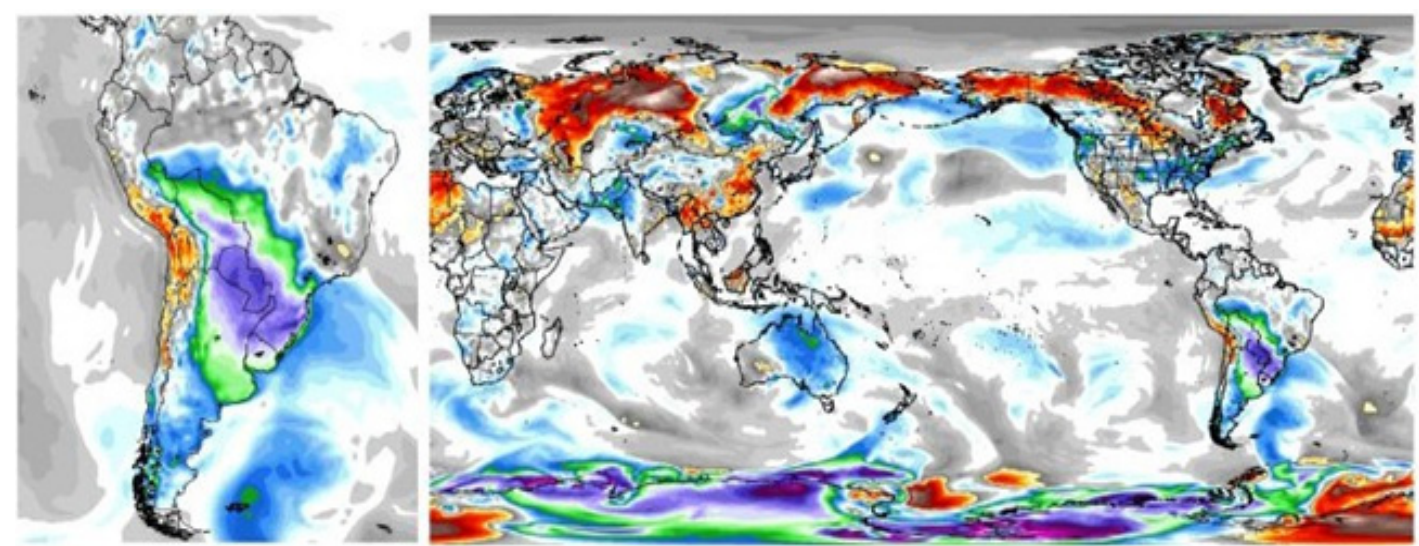

Anomalia negativa de temperatura no Centro da América do Sul amanhã e na sexta será a maior no planeta fora das regiōes polares (Cortesia Dr. Ryan Maue)

Fonte: Metsul Meteorologia, 2012.

Também no dia 08 de junho de 2012, houve a ocorrência de geadas, conforme a figura 9 e em Santa Maria/RS foi verificada a menor temperatura mínima para a cidade nos últimos 10 anos conforme reportagem da figura 10 .

Figura 9 - Geada em parreiral da Serra Gaúcha.

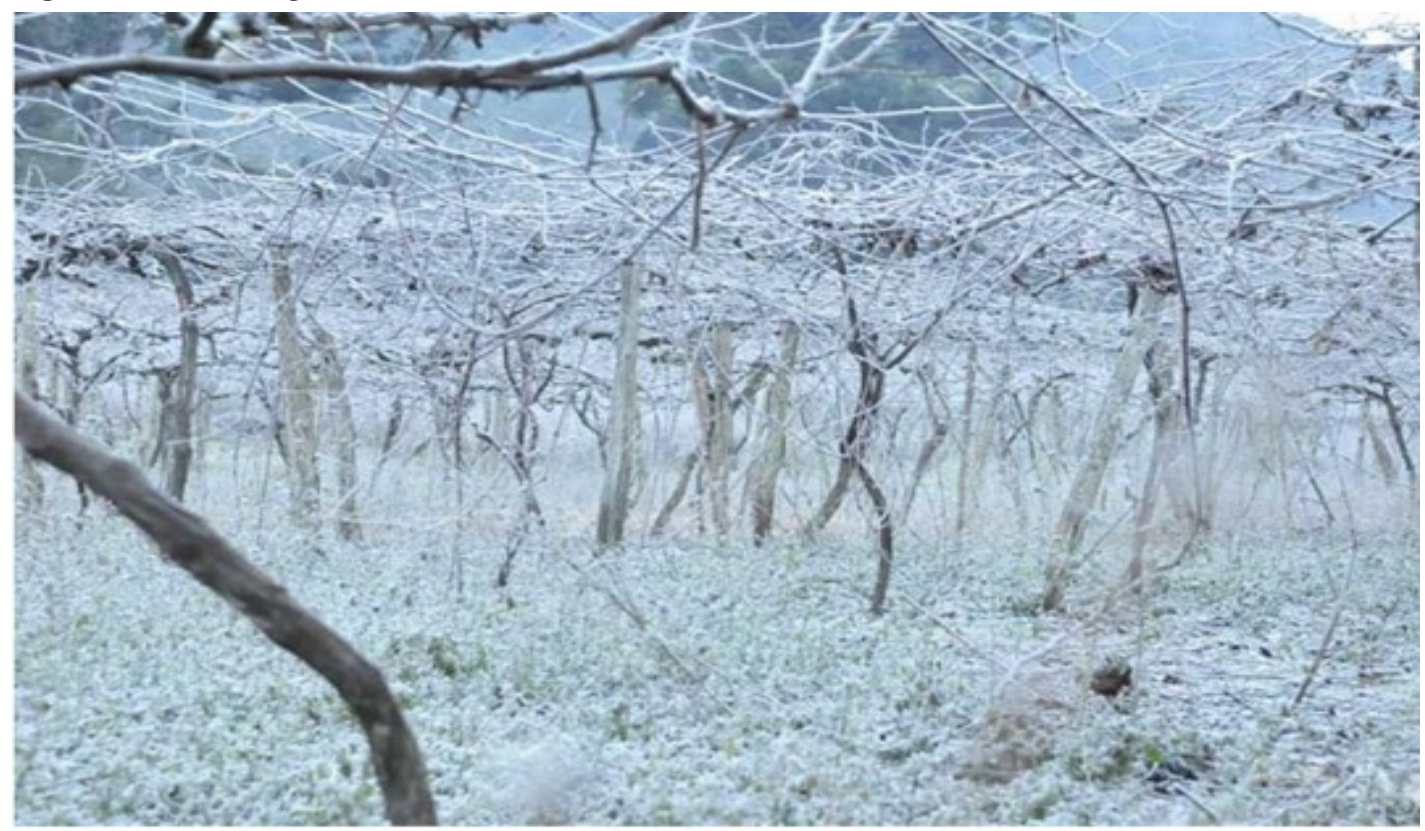

Geada forte em parreiral em vale da Serra Gaúcha / Halder Ramos do Correio do Povo

Geografia Ensino \& Pesquisa, v. 17, n.2 p. 213-226, maio/ago. 2013

Costa, E. R. da.

Fonte: Metsul Meteorologia, 2012. 
Figura 10- Reportagem sobre o dia mais já registrado em Santa Maria/RS nos últimos 10 anos.

\section{O dia mais frio em 10 anos}

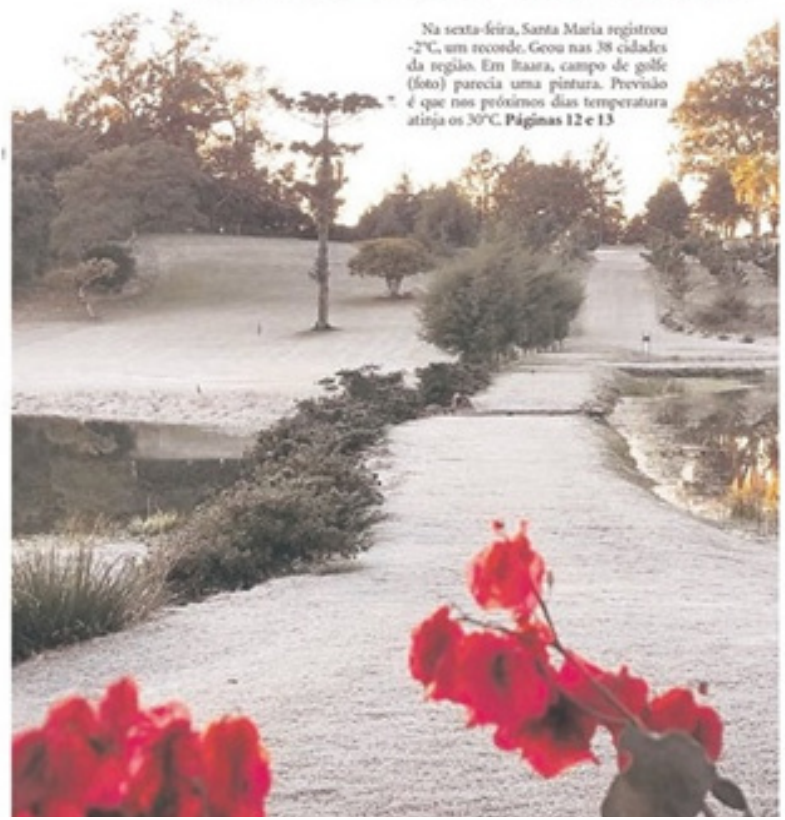

Fonte: Metsul Meteorologia, 2012.

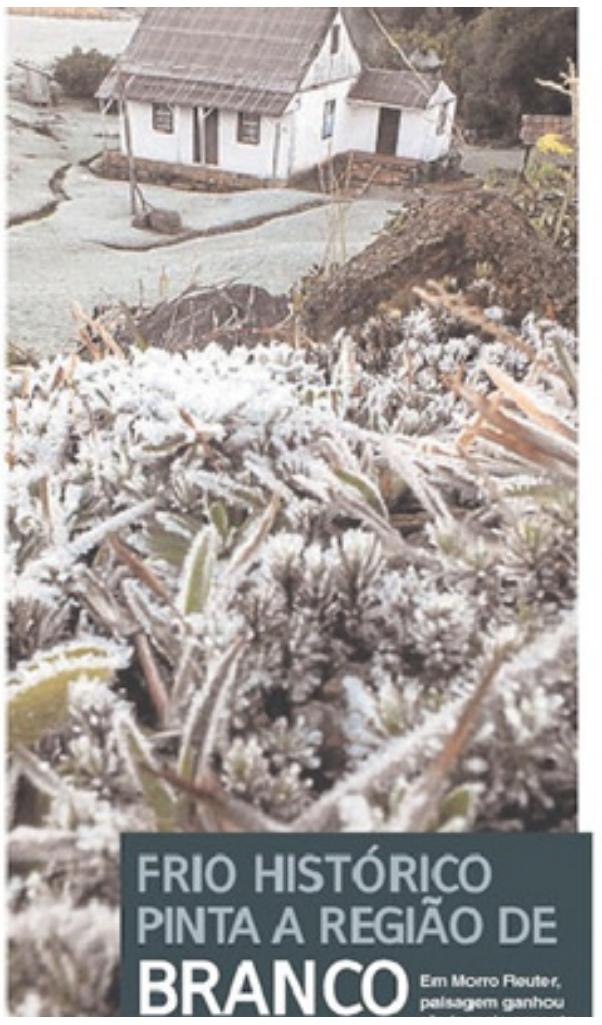

No dia 09 de junho de 2012 a onda de frio começa a perder força no Estado do Rio Grande do Sul, sendo que as temperaturas mínimas registradas se apresentaram mais altas do que nos dias anteriores, mas mantendo-se negativas em algumas estações meteorológicas.

A temperatura mínima mais baixa foi registrada em Canela e Farroupilha $\left(-6,3^{\circ} \mathrm{C}\right)$ ambas localizadas na Serra do Nordeste, onde são encontradas as maiores altitudes do Estado. Já a temperatura mínima mais alta foi registrada em Tramandaí $\left(3,4^{\circ} \mathrm{C}\right)$, localizada no Litoral (quadro 4).

Quadro 4 - Temperaturas mínimas registradas em algumas estações do INMET (Instituto Nacional de Meteorologia) do Estado do Rio Grande do Sul no dia 09 de junho de 2012.

\begin{tabular}{|c|c|c|c|c|c|}
\hline Canela & $-6,3^{\circ} \mathrm{C}$ & Ibirubá & $-2,0^{\circ} \mathrm{C}$ & Livramento & $0,1^{\circ} \mathrm{C}$ \\
\hline Farroupilha & $-6,3^{\circ} \mathrm{C}$ & Santa Maria & $-1,8^{\circ} \mathrm{C}$ & Cruz Alta & $0,2^{\circ} \mathrm{C}$ \\
\hline Santa Rosa & $-5,8^{\circ} \mathrm{C}$ & Ausentes & $-1,4^{\circ} \mathrm{C}$ & Iraí & $0,2^{\circ} \mathrm{C}$ \\
\hline São Gabriel & $-4,0^{\circ} \mathrm{C}$ & Chui & $-1,4^{\circ} \mathrm{C}$ & Passo Fundo & $0,3^{\circ} \mathrm{C}$ \\
\hline Quaraí & $-3,9^{\circ} \mathrm{C}$ & Campo Bom & $-1,1^{\circ} \mathrm{C}$ & P. das Missöes & $0,7^{\circ} \mathrm{C}$ \\
\hline São Leopoldo & $-3,8^{\circ} \mathrm{C}$ & L. Vermelha & $-1,0^{\circ} \mathrm{C}$ & São L. Gonzaga & $0,7^{\circ} \mathrm{C}$ \\
\hline Rosário do Sul & $-3,4^{\circ} \mathrm{C}$ & Jaguarão & $-0,8^{\circ} \mathrm{C}$ & Caxias do Sul & $1,2^{\circ} \mathrm{C}$ \\
\hline Bom Jesus & $-3,0^{\circ} \mathrm{C}$ & Alegrete & $-0,7^{\circ} \mathrm{C}$ & Torres & $1,3^{\circ} \mathrm{C}$ \\
\hline Cambará & $-3,0^{\circ} \mathrm{C}$ & B. Gonçalves & $-0,7^{\circ} \mathrm{C}$ & F. Westphalen & $1,7^{\circ} \mathrm{C}$ \\
\hline Pelotas & $-3,0^{\circ} \mathrm{C}$ & Camaquã & $-0,7^{\circ} \mathrm{C}$ & Santo Augusto & $1,8^{\circ} \mathrm{C}$ \\
\hline Três Coroas & $-3,0^{\circ} \mathrm{C}$ & Porto Alegre & $-0,7^{\circ} \mathrm{C}$ & Riozinho & $1,9^{\circ} \mathrm{C}$ \\
\hline Vacaria & $-2,8^{\circ} \mathrm{C}$ & Rio Grande & $-0,5^{\circ} \mathrm{C}$ & Caçapava & $2,2^{\circ} \mathrm{C}$ \\
\hline Bagé & $-2,7^{\circ} \mathrm{C}$ & Lajeado & $-0,4^{\circ} \mathrm{C}$ & Encruzilhada & $2,4^{\circ} \mathrm{C}$ \\
\hline Dom Pedrito & $-2,7^{\circ} \mathrm{C}$ & Uruguaiana & $-0,3^{\circ} \mathrm{C}$ & São Borja & $2,7^{\circ} \mathrm{C}$ \\
\hline São F. de Paula & $-2,4^{\circ} \mathrm{C}$ & Rio Pardo & $-0,2^{\circ} \mathrm{C}$ & Canguçu & $3,2^{\circ} \mathrm{C}$ \\
\hline Teutônia & $-2,4^{\circ} \mathrm{C}$ & Erechim & $-0,1^{\circ} \mathrm{C}$ & Mostardas & $3,3^{\circ} \mathrm{C}$ \\
\hline São Marcos & $-2,3^{\circ} \mathrm{C}$ & Soledade & $0,1^{\circ} \mathrm{C}$ & Santiago & $3,4^{\circ} \mathrm{C}$ \\
\hline Garibaldi & $-2,2^{\circ} \mathrm{C}$ & Santa Vitória & $0,1^{\circ} \mathrm{C}$ & Tramandaí & $3,4^{\circ} \mathrm{C}$ \\
\hline
\end{tabular}

Fonte: Metsul Meteorologia, 2012.

A onda de frio de junho de 2012 no Rio Grande do Sul: gênese, duração e temperaturas...

Geografia Ensino \& Pesquisa, v. 17, n.2 p. 213-226, maio/ago. 2013 
No dia 10 de junho de 2012, a onda de frio deixou de existir, pois houve um gradativo aquecimento da Massa Polar Continental que passou a condição de Massa Polar Aquecida. Nos dias seguintes a temperatura se elevou sendo que a temperatura máxima registrada em Porto Alegre/RS no dia 12 de junho foi de $27^{\circ} \mathrm{C}$. No dia 15 de junho como mencionado anteriormente houve a chegada de uma nova Frente Polar Atlântica que produziu chuva significativa e após isto um novo domínio da Massa Polar Atlântica sobre as condições de tempo no Estado do Rio Grande do Sul.

\section{Considerações finais}

A onda de frio ocorrida no Estado do Rio Grande do Sul entre os dias 06 e 10 de junho de 2012 teve sua origem associada à Massa Polar Continental, como todas que ocorrem ou já ocorreram no Estado.

Os fatores estáticos ou geográficos do clima como a altitude e a continentalidade potencializam os efeitos térmicos da onda de frio em algumas regiões ecoclimáticas do Estado como o Planalto Médio, Alto Uruguai, Missioneira, Baixo Vale do Uruguai, Campanha Gaúcha, Serra do Nordeste e Serra do Sudeste; já a ação termorreguladora das massas líquidas (maritimidade) associadas às baixas altitudes amenizam a queda térmica no Litoral, Região das grandes lagoas, Depressão Central e Encosta Inferior da Serra do Nordeste.

A onda de frio de junho de 2012 foi uma das maiores já ocorridas no Estado do Rio Grande do Sul nos últimos dez anos e provocou temperaturas mínimas extremamente baixas (abaixo de $0^{\circ} \mathrm{C}$ ) para quase todas as regiões ecoclimáticas. Algumas cidades registraram recordes negativos de temperatura como em Santa Rosa que a temperatura mínima chegou à $-7,8^{\circ} \mathrm{C}$ no terceiro dia da onda de frio.

A onda de frio de junho 2012 foi tão intensa que provocou forte anomalia térmica negativa em grande parte do Cone-Sul da América do Sul, o que fez com a mesma se apresentase durante o fenômeno como a região mais fria da Terra depois das regiões polares.

\section{Referências}

ARAÚJO, S.M.B. Estudo da variabilidade climática em regiões homogêneas de temperaturas médias do ar no RioGrande do Sul. 2005. 69f. Dissertação (Mestrado em Ciências) - Universidade Federal de Pelotas, Pelotas, 2005.

CPTEC/INPE. Imagens de Satélites. Cachoeira Paulista/SP, 2012. Disponível em: < http://satelite. cptec.inpe.br/acervo/goes_anteriores.jsp>. Acesso em: 20 jun.2012.

COSTA, E.R.da.; SARTORI, M.G.B.; FANTINI, V. Estudo da relação entre eventos elniño-laniña e ocorrência de ondas de frio na região de Santa Maria-RS. Boletim Gaúcho de Geografia, n.33, p.263-276, 2007.

INSTITUTO NACIONAL DE METEOROLOGIA. Dados climáticos. Brasília, DF, 2012. Disponível em: http://www.inmet.gov.br/portal/. Acesso em: 12 jun.2012.

MACHADO, F. P. Contribuição ao estudo do clima do Rio Grande do Sul. Rio de Janeiro: IBGE, 1950, 91p.

MARINHA DO BRASIL. Cartas Sinóticas. Niterói/RJ, 2012. Disponível em: <https://www.mar.mil. $\mathrm{br} / \mathrm{dhn} / \mathrm{chm} / \mathrm{meteo} / \mathrm{prev} / \mathrm{cartas} /$ cartas.htm. Acesso em: 25 jun.2012.

METSUL. Reportagens sobre a onda de frio de junho de 2012. Porto Alegre/RS, 2012. Disponível em: <http://www.metsul.com/blog2012>. Acesso em: 19 jun.2012.

ROMERO, H.A.; MENDONÇA, M. Ondas de Frío registradas em invierno de 2010: necesidad de una perspectiva regional integrada para la Climatología Latinoamericana. In: XIII ENCONTRO DE GEÓGRAFOS LATINOAMERICANOS, 2011, San José. Anais... XIII Encontro de Geógrafos Latinoamericanos., 2011.

SARTORI, M. G. B. A dinâmica do clima do Rio Grande do Sul: indução empírica e conhecimento científico. Terra Livre, v.1, n.20, p.27-49, 2003.

Geografia Ensino \& Pesquisa, v. 17, n.2 p. 213-226, maio/ago. 2013

Costa, E. R. da. 


\section{Correspondência:}

Eduíno Rodrigues da Costa - Universidade Estadual Paulista "Júlio de Mesquita Filho" - UNESP/ Presidente Prudente - Faculdade de Ciência e Tecnologia. Rua Roberto Simonsen, 305. Centro Educaciona, Presidente Prudente - SP, CEP 19060-900.

E-mail: eduinocosta@gmail.com

Recebido em 08 de fevereiro de 2013.

Revisado pelo autor em 24 de março de 2013.

Aceito para publicação em 28 de março de 2013. 